\title{
First Results from a Solar-Biomass Hybrid System for the Production of Solar Carbon
}

\author{
Hans Grassmann1,2*, Marco Citossi' ${ }^{1}$, Renato Bernes ${ }^{3}$, Andrea Piani ${ }^{1,3}$ \\ ${ }^{1}$ Dipartimento Politecnico di Ingegneria e di Architettura (DPIA), University of Udine, Udine, Italy \\ ${ }^{2}$ Isomorph s.r.l., Trieste, Italy \\ ${ }^{3}$ A \& T2000 Spa, Codroipo (UD), Italy \\ Email: `hans.grassmann@uniud.it, marco.citossi@uniud.it
}

How to cite this paper: Grassmann, $\mathrm{H}$., Citossi, M., Bernes, R. and Piani, A. (2020) First Results from a Solar-Biomass Hybrid System for the Production of Solar Carbon. Smart Grid and Renewable Energy, 11, 21-28.

https://doi.org/10.4236/sgre.2020.112002

Received: February 9, 2020

Accepted: February 25, 2020

Published: February 28, 2020

Copyright (C) 2020 by author(s) and Scientific Research Publishing Inc.

This work is licensed under the Creative Commons Attribution International License (CC BY 4.0).

http://creativecommons.org/licenses/by/4.0/

\section{Open Access}

\begin{abstract}
Solar energy as well as biomass energy techniques suffers from disadvantages, which in some cases limit their potential for substituting fossil fuels. For instance, solar energy is difficult to store, and many kinds of biomass are not suited for combustion, in spite of the fact that they have high energy contents. We describe and industrial size system, which has the goal of overcoming some of these limitations by combining solar- and biomass power. This is achieved by roasting residual biomass by means of hot air provided by solar power only. The solar power is collected by three "Linear Mirror" solar concentrator, they are designed to achieve high efficiency also at northern latitudes. Each one is equipped with an innovative solar-air heat exchanger. The hot air is delivered to a roasting device filled with humid residual biomass. We report the performance of this system from a first commissioning run. The system is intended to help create a closed-cycle economy by means of transforming waste biomasses to a high-quality combustible.
\end{abstract}

\section{Keywords}

Renewable Energy, Solar Biomass Conversion, Concentrated Solar Power, Solar Carbon, Solar Pyrolysis, Linear Mirror, Solar Heat Exchanger

\section{Introduction}

Over the last years, there has been a strong increase in the use of solar energy for electricity production [1], while instead its use to provide thermal power is still quite low [2]. In particular, this is true for the elevated temperatures, which are required for industrial processes (typically $>100^{\circ} \mathrm{C}$ ).

This is in part due to the fact that for concentrated solar plants, usually para- 
bolic troughs are used, which are very inefficient at northern latitudes since they follow the sun only in one spatial direction. Usually they are installed in the north-south direction and follow the path of the sun from east to west during the day. Therefore, at northern latitudes, for most of the time the solar radiation arrives at a small angle, causing a corresponding loss of performance.

Also the use of biomasses for providing thermal energy is rather limited at the time being [3]. So that, all in all, almost all the thermal energy is still provided by fossil fuels [4]. This situation persists in spite of the fact that a large fraction of available biomasses are not being used, but rather treated as waste and discharged.

There are several reasons for the very limited use of the available biomasses. First, only some particular kinds of biomass, like for instance wood from deciduous trees, burn well. Since in most parts of the world the consumption of wood is already too high compared to its growth, the use of these high-quality biomasses cannot be much increased without disturbing the natural cycles.

Secondly, the technologies for combusting or gasifying biomasses are rather expensive, compared to what is needed for combusting fossil fuels [5]. This cost problem is increased by the fact that there are different kinds of biomasses with different mechanical properties and combustion properties. As a consequence many different material transport systems, burners or gasifiers do exist. Fossil fuels, instead, are offered in standardized forms and are being burnt by simple and standardized technical devices.

In this article we suggest an innovative way to overcome those limitations by combining solar and biomass, and by making use of a new solar concentrating tool: the Linear Mirror allows to harvest solar energies at temperatures of up to $200^{\circ} \mathrm{C}$ also at northern latitudes, this energy is stored for long periods of time in the form of roasted biomass, waste biomass, which usually cannot be used for energy production is made useful by means of air heated by the solar radiation, and moreover the presented device is not just an experimental one, but rather is suited for the industrial application.

This paper presents the use of solar energy harvested by a Linear Mirror (Chapter 3.1) for heating air efficiently and at elevated temperatures with an innovative kind of heat exchanger (Chapter 3.2), in order to toast or torrefy waste biomasses, even very humid ones (Chapter 3.3). The results from the first commissioning run are described in Chapter 4.

In order to explain the motivation of this work, previous research on the topic of pyrolysis and solar pyrolysis is discussed in Chapter 2.

\section{Solar Pyrolysis of Simple Biomasses}

It is generally known that the combustion quality of biomasses can be improved by means of pyrolytic heating ( $T \gg 300^{\circ} \mathrm{C}$, absence of oxygen), which transforms the biomasses to vegetal coal [6]. In an earlier work, we have therefore constructed and successfully operated a prototype device, which used concen- 
trated solar energy for heating waste biomasses to about $300^{\circ} \mathrm{C}$ [7]. The device consisted of a rotary furnace containing the biomass, the outside surface of the furnace being heated by concentrated solar energy.

Solar pyrolysis has two particular advantages: First, all or almost all kinds of biomass can be processed, also very humid ones. Second, regardless of the nature of the original material, the resulting vegetal carbon will always consist mostly of carbon atoms [8].

However, heating biomass to $300^{\circ} \mathrm{C}$ or more has also some disadvantages: First, a large fraction of the energy initially contained in the biomass is lost during heating, typically $50 \%$ or more [8].

Second, in order to heat the biomass to $300^{\circ} \mathrm{C}$ in the rotary furnace, its walls have to be heated to well above $400^{\circ} \mathrm{C}$, with a corresponding increase of energy loss to the environment.

Third, above $300^{\circ} \mathrm{C}$, the volatile part of the biomass is emitted as a dense fume, which in the case of an industrial application would need to be processed or cleaned, increasing the technical complexity of the setup.

These disadvantages can be avoided by roasting biomasses making use of solar energy, and by gasifying the resulting material, instead of burning it in an open flame: materials like humid wood, green cut, potatoes, used coffee powder, yogurt or maize do not burn and cannot be gasified or can be gasified only using complicated technical systems incorporating some kind of pre-treatment of the material. However, if one heats these materials to $130^{\circ} \mathrm{C}$ (slight roasting), they become high quality combustibles and can be easily gasified in a simple gasifier. Such a temperature is routinely used in a normal kitchen for preparing food, and does not usually result in the production of fumes or other kinds of hazard.

It is then the scope of this paper, to present a setup, which allows to roast biomasses using solar energy, and to evaluate its performance. The material produced will be referred to as "solar carbon", since it can substitute fossil fuels in many applications.

The apparatus presented in this paper was commissioned by the environmental company A \& T2000 SpA (Udine, Italy) ${ }^{1}$ and was designed to be able to process quantities relevant for the industrial application.

\section{Setup}

The system consists of three parts: 1) a Linear Mirror, which concentrates solar radiation on 2) a solar-air heat exchanger, which provides hot air for 3) a roasting device containing the biomass. Figure 1 shows the plant at the A \& T2000 site.

\subsection{The Linear Mirrors}

In short, a Linear Mirror system consists of an array of eight reflecting mirrors.

\footnotetext{
${ }^{1} \mathrm{~A} \&$ T2000 processes urban waste, producing also electrical energy from it, and it collects large amount of waste wood material, in part from agricultural industries, in part from construction and from other sources.
} 


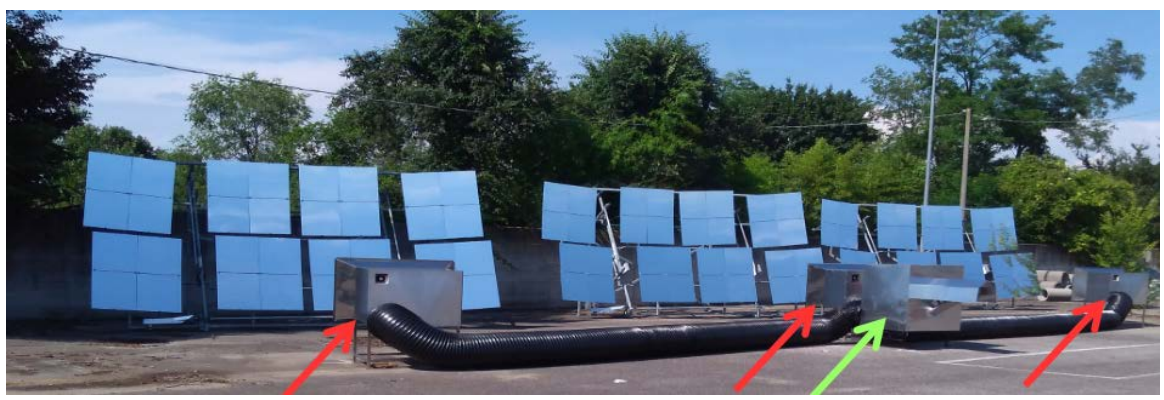

Figure 1. The installation at the A \& T2000 site. The heat exchangers are indicated with red arrows, the toaster with a green arrow.

Each mirror is mounted on a rod normal to the mirror surface, this rod forms the diagonal of an Euclidean kite (sometimes also called deltoid). One side of the deltoid is always pointing to the solar absorber (which remains always in the same position), and one side is pointing towards the sun. This is described in more detail in [9]. The eight deltoids are mechanically connected to each other, so that three small electrical motors can move all mirrors concurrently, reflecting the sun light onto the common heat exchanger. In comparison, a conventional system of eight heliostats would need 16 motors to achieve the same effect. Each of the eight mirrors is composed of four sections, which are slightly inclined with respect to each other, in order to further increase the light concentration of the system.

Compared to a parabolic dish, the Linear Mirror has the advantage that the solar absorber remains always in a fixed position, close to the ground. Compared to a parabolic trough it has the advantage of having a larger efficiency at northern latitudes - its geometrical efficiency in winter is as large as in summer.

Each Linear Mirror is controlled by a Siemens Logo PLC.

\subsection{Solar-Air Heat Exchanger}

A more detailed description and theoretical discussion of the solar-air heat exchanger can be found in [10]. In short, the absorbing surface consists of polished steel plates, with a low overall emissivity. The steel plates are inclined with respect to each other in such a way that light coming from the mirrors undergoes multiple reflections between the plates. With respect to this direction then, the absorptivity is rather large. Unlike conventional solar absorbers, this one is therefore not selective with respect to the wavelength, but with respect to the direction of the light propagation. The absorber is able to provide hot air up to a temperature of $200^{\circ} \mathrm{C}$ with a rather high efficiency (for more details see [9]). An EBM Papst axial fan (3214JH3-ENU) is enough to create an air flow of up to 9 $\mathrm{kW}$ of thermal power, operating the fan at a tension between $12 \mathrm{~V}$ (minimum nominal voltage) and $16 \mathrm{~V}$ (at $24 \mathrm{~V}$ the fan has a power of $30 \mathrm{~W}$ ).

\subsection{Roasting Device}

The biomass is roasted in a container with a section of $0.8 \mathrm{~m} \times 0.8 \mathrm{~m}, 1.6 \mathrm{~m}$ 
high. The hot and dry air from the solar-air heat exchanger enters through the bottom of the container, and leaves it through the top at a lower temperature and a higher humidity. The biomass is removed from the container by means of a conveyor screw at the bottom of the container. The screw is controlled by a temperature sensor, which is mounted $0.4 \mathrm{~m}$ above the bottom, at the center of the container: when the temperature at this point exceeds a fixed threshold, the screw begins to turn, until the temperature of the control sensor falls below the threshold. For the measurements described below, the temperature threshold was set in the range between $120^{\circ} \mathrm{C}$ and $130^{\circ} \mathrm{C}$.

The roasting device is controlled by a Siemens Logo plc, the temperature sensors are PT100 elements, which are read by the corresponding Siemens Logo readout modules. The Logo module for the roasting device is connected to the Logo control modules of the Linear Mirrors. Since the Logo plc also is a web server, all four Logo modules can be directly accessed through an Ethernet Internet connection. Therefore the setup is prepared to be an element of the IOT (Internet of things) in an industry 4.0 environment.

\section{Results}

The data presented in the following have been collected in the first commissioning run of the system, at the A \& T2000 site, at Pozzuolo del Friuli ( $46^{\circ}$ North), on January 11,2020 . Sunrise (sunset) was at 7:40 am (04:35 pm), the maximum sun zenith was $22^{\circ}$. Ambient temperature was between $0^{\circ} \mathrm{C}$ and $5^{\circ} \mathrm{C}$.

The wood chips to be processed had been exposed to rain for several months, being then very wet.

At 10:31 the plant was switched on, exposing the solar-air heat exchanger to the concentrated sun-light. Figure 2 shows the temperature of the air entering the roaster device and the temperature of the control sensor, mounted $0.4 \mathrm{~m}$ above the bottom of the device and at its center.

At 10:55 - 24 minutes after having started the measurement the biomass roaster was filled with $92 \mathrm{~kg}$ of material. This event can be seen in the temperature curve of the control sensor (blue line): the temperature, which previously was raising continuously, falls now due to the lower temperature of the biomass, forming a peak structure centered at the time of 24 minutes on the $\mathrm{x}$-axis.

After 159 minutes the biomass in the lower section of the roaster reached $130^{\circ} \mathrm{C}$, and the conveyor screw begun to remove material. As material was removed, new material was added by hand (the device does not yet have an automatic feeding mechanism). To the $92 \mathrm{~kg}$ of material initially put inside the roasting device, additional $76 \mathrm{~kg}$ of material were added during the day, a total of $168 \mathrm{~kg}$ of input material was processed.

After 14.34 (243 minutes on the $\mathrm{x}$-axis of the figure) the conveyor screw was not activated anymore, and no new material was filled in. After that time the material in the container continued to be desiccated at temperatures around $100^{\circ} \mathrm{C}$. One can see from Figure 2, that even at 16:00 (329 minutes), half an hour 


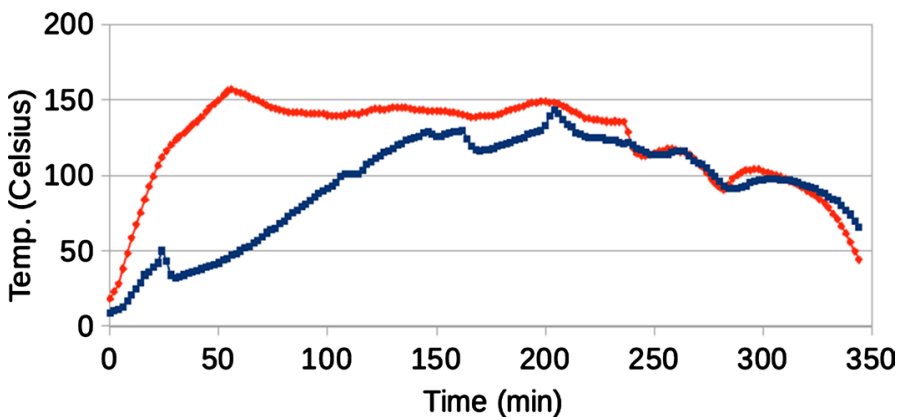

Figure 2. Air temperature (red) and biomass temperature (blue) as a function of time in the solar roaster during the first day of commissioning of the A \& T2000 solar-biomass plant.

before sunset and with the sun only $5^{\circ}$ above the horizon, the plant still provided hot air at a temperature of $90^{\circ} \mathrm{C}$.

The mass of the material (which was $168 \mathrm{~kg}$ before processing) was again measured after sunset, it was now $94 \mathrm{~kg}$. This corresponds to a mass reduction of $74 \mathrm{~kg}$ within a time interval of 5.2 hours, corresponding to an average mass reduction rate of $74 \mathrm{~kg} / 5.2 \mathrm{~h}=14 \mathrm{~kg} / \mathrm{h}$. Correspondingly, the humidity of the raw material was at least $74 / 168=44 \%$.

During most of the day the upper surface of the biomass had a temperature of about $45^{\circ} \mathrm{C}$, which means that at an ambient temperature of $5^{\circ} \mathrm{C}$ the heat energy was transferred to the material with an efficiency of typically $\left(135^{\circ} \mathrm{C}-\right.$ $\left.45^{\circ} \mathrm{C}\right) / 135^{\circ} \mathrm{C}=0.7$. Since $0.7 \mathrm{kWh}$ of heat energy are needed in order to evaporate one liter of water, in average $14 \mathrm{~kW}$ of heat energy were used for evaporating water during this day and two $\mathrm{kW}$ for heating this water to $100^{\circ} \mathrm{C}$, for a total of $16 \mathrm{~kW}$. This compares reasonably well with the maximum power of $24 \mathrm{~kW}$ delivered by the three mirrors at noon [9].

Assuming 1.200 sun hours per year, the plant should be able to process $(1.200 / 5.2) \times 0.17 \mathrm{t}=39$ tons of very humid material (44\%) per year, corresponding to 10 tons of heating oil. For less humid input material, the production should be higher.

By means of a heat exchanger most of this energy could be recovered and used again, resulting in a further increase in production. Thanks to the high temperature provided by the Linear Mirror, in a future plant also a multi stage desiccation system could be possible, similar to those used for the desalination of sea water. In this case the production could be increased also by a large factor.

\section{Outlook}

A temperature of $130^{\circ} \mathrm{C}$ is enough for processing wood chips, since the resulting slightly roasted material burns and gasifies quite well. For other biomasses, higher temperatures might be needed in order to transform them to good combustibles.

For the A \& T2000 plant, the solar-air heat exchanger is operated in an open circuit. Therefore it must provide air at temperatures beyond the ignition tem- 
perature of the biomass used, since otherwise the biomass in the roasting device would burn.

If later on higher temperatures should be needed, the solar-air heat exchanger can also be operated in a closed circuit. Above a biomass temperature of $100^{\circ} \mathrm{C}$ the closed circuit automatically would be filled with water vapor and contain only small traces of oxygen, so that the biomass could be exposed also to elevated temperatures without burning. Whether this option will have to be implemented, will be the subject of further studies.

\section{Conclusions}

During its first commissioning run, the system of three Linear Mirrors with solar-air heat exchangers and a biomass roasting device worked well according to expectations. From the measured performance one can extrapolate that the plant will be able to process about 39 tons of very humid biomass per year, transforming it to a high quality combustible referred to as "solar carbon".

The plant is able to roast all kinds of biomass, not only wood.

The production of solar carbon does not only recover the energy contained in the biomass, which would otherwise be lost during the decomposition of the material, but it is also a way to store solar energy, since the A \& T2000 plant is operated only with solar radiation.

\section{Conflicts of Interest}

The authors declare no conflicts of interest regarding the publication of this paper.

\section{References}

[1] Kabir, E., Kumar, P., Kumar, S., Adelodun, A.A. and Kim, K.-H. (2018) Solar Energy: Potential and Future Prospects. Renewable and Sustainable Energy Reviews, 82 894-900. http://www.sciencedirect.com/science/article/pii/S1364032117313485 https://doi.org/10.1016/j.rser.2017.09.094

[2] Avezova, N.R., Khaitmukhamedov, A.E., Usmanov, A.Y., et al. (2017) Solar Thermal Power Plants in the World: The Experience of Development and Operation. Applied Solar Energy, 53, 72-77. https://doi.org/10.3103/S0003701X17010030 https://link.springer.com/article/10.3103/S0003701X17010030

[3] Teske, S., et al. (2016) Solar Thermal Electricity: Global Outlook 2016. European Solar Thermal Electricity Association, Brussels.

[4] IEA (2019) World Energy Outlook 2019. IEA, Paris. https://www.iea.org/reports/world-energy-outlook-2019

[5] Yao, Z.Y., You, S.M., Ge, T.S. and Wang, C.-H. (2018) Biomass Gasification for Syngas and Biochar Co-Production: Energy Application and Economic Evaluation. Applied Energy, 209, 43-55. https://doi.org/10.1016/j.apenergy.2017.10.077 https://www.sciencedirect.com/science/article/abs/pii/S0306261917315003?via\%3Di hub

[6] Production of Solid Sustainable Energy Carriers from Biomass by Means of Torrefaction, Project Funded from the European Union's Seventh Programme for Re- 
search, Technological Development and Demonstration under Grant Agreement No. 282826. https://www.sector-project.eu

[7] Grassmann, H., Boaro, M., Citossi, M., Cobal, M., Ersettis, E., Kapllaj, E. and Pizzariello, A. (2015) Solar Biomass Pyrolysis with the Linear Mirror II. Smart Grid and Renewable Energy, 6, 179-186. https://doi.org/10.4236/sgre.2015.67016

[8] Citossi, M. (2018) A Preliminary Study to Produce Solar Carbon. PhD Thesis, University of Udine, Udine.

[9] Grassmann, H., et al. (2013) First Measurements with a Linear Mirror Device of Second Generation. Smart Grid and Renewable Energy, 4, 253-258. https://doi.org/10.4236/sgre.2013.43030

[10] Grassmann, H. and Citossi, M. (2019) Development and Test of a New Solar-Air Heat Exchanger for the Linear Mirror II System. Smart Grid and Renewable Energy, 10, 155-164. https://doi.org/10.4236/sgre.2019.105010

[11] Rachel, N., Carmody, R. and Wrangham, W. (2009) The Energetic Significance of Cooking. Journal of Human Evolution, 57, 379-391.

https://doi.org/10.1016/j.jhevol.2009.02.011 